\title{
NORMS OF SUMMABILITY AND HAUSDORFF MEAN MATRICES ON DIFFERENCE SEQUENCE SPACES
}

\section{HADI ROOPAEI}

Abstract. In this paper, we compute the norms of summability and Hausdorff mean matrices on difference sequence space $b v_{p}$. Moreover, as an application, we derive the main result of [5].

Mathematics subject classification (2010): 26D15, 40C05, 40G05, 47B37.

Keywords and phrases: Matrix operator, norm, Hausdorff matrix, difference sequence space.

\section{REFERENCES}

[1] F. BAŞAR, Summability Theory and Its Applications, Bentham Science Publishers, e-books, Monographs, İstanbul, 2012.

[2] D. Foroutannia And H. Roopaei, The norms and the lower bounds for matrix operators on weighted difference sequence spaces, U.P.B. Sci. Bull., Series A, 79(2)(2017), 151-160.

[3] G. H. Hardy, J. E. LitTlewood, and G. Polya, Inequalities, 2nd edition, Cambridge University press, Cambridge, 2001.

[4] H. KizmaZ, On certain sequence spaces I, Canad. Math. Bull., 25(2)(1981), 169-176.

[5] R. LASHKARIPOUR AND J. FATHI, Norms of matrix operators on $b v_{p}$, J. Math. Inequal., 6 (2012), No. 4, 589-592.

[6] H. Roopaei And D. Foroutannia, The norms of certain matrix operators from $l_{p}$ spaces into $l_{p}\left(\Delta^{n}\right)$ spaces, Linear and Multilinear Algebra, 67(4)(2019), 767-776. 